\title{
КОМОРБІДНІСТЬ ЦУКРОВОГО ДІАБЕТУ 2 ТИПУ ТА ДИФУЗНОГО ЗОБА: ДАНІ ЛАБОРАТОРНОГО ДОСЛІДЖЕННЯ
}

Коморбідність цукрового діабету 2 типу та дифузного зоба: дані лабораторного дослідження

\section{В. А. Мусієнко, М. І. Марущак}

Тернопільський національний медичний університет імені І. Я. Горбачевського мОЗ України

Резюме. У світі спостерігається тенденція до збільшення поширеності цукрового діабету 2 типу та дифрузного нетоксичного зоба. Повідомляється, що у пацієнтів із порушеним метаболізмом глюкози простежується більший об'єм щитоподібної залози та більша поширеність вузлів. Останнім часом науковці все більше приділяють уваги вивченню зв'язку між інсулінорезистентністю та аномальною фрункцією і морорологією щитоподіної залози.

Мета дослідження - оцінити лабораторні показники у хворих із поєднаним перебігом цукрового діабету 2 типу та дифрузим нетоксичним зобом і виявити можливі маркери їх коморбідності.

Матеріали і методи. Для дослідження було виконано аналіз медичної документації 541 пацієнта. Сорормовано дві дослідні групи: 40 осіб із дифрузним нетоксичним зобом (ДНЗ) та цукровим діабетом 2 (ЦД2) типу і 501 пацієнт з діабетом 2 типу без патології щитоподібної залози. Кожному хворому виконували ультразвукове дослідження щ3. Об'єм частки розраховували за методом Bruno. Buзначали показники ліпідного профрілю, показники загального аналізу крові, рівень інсуліну, концентрацію глюкози, показники біохімічного аналізу крові, рівні гормонів щитоподібної залози (ТTГ, $T_{4}$ ). Описову статистику здійснювали у вигляді розрахунку медіани (Me) та нижнього $(L q)$ i верхнього (Uq) квартилів. При оцінці рівня статистичноі значущості проводили попарне порівняння груп з використанням U-критерію Манна - Уітні.

Результати. Середній вік хворих у групі - 56 років. При аналізі показників загального аналізу крові було виявлено вірогідно вищі показники ШОЕ - на 63,6 \% у групі ЦД2 + ДНЗ порівняно з ЦД2. При оцінці показників вуглеводного обміну встановлено вірогідно вищі показники глікозильованого гемоглобіну на 7,4 \% у групі ЦД2 + ДНЗ порівняно з ЦД2. Показники не-ХС-лПВЩ на 3,57 \% вищі у групі ЦД2 + ДНЗ порівняно з ЦД2. Відмічається тенденція до підвищення загального та залишкового холестеролу в групі ЦД2 + ДНЗ порівняно з ЦД2.

Висновки. У пацієнтів із поєднаним перебігом цукрового діабету 2 типу та дифрузного нетоксичного зоба виявляються вірогідно вищий рівень ШОЕ, гліко-
Comorbidity of type 2 diabetes mellitus and diffused non-toxic goiter: laboratory data

\section{A. Musiienko, M. I. Marushchak}

I. Horbachevsky Ternopil National Medical University

e-mail: marushchak@tdmu.edu.ua

Summary. The prevalence of type 2 diabetes and diffuse non-toxic goiter increases worldwide. It has been reported that patients with impaired glucose metabolism have larger thyroid volumes. The researchers have increasingly focused on studying the relationship between insulin resistance and abnormal thyroid function and morphology.

The aim of the study - to evaluate laboratory data in patients with comorbidity of type 2 diabetes mellitus and diffuse non-toxic goiter and identify possible markers of their comorbid course.

Materials and Methods. The study included medical records of 541 patients. Two experimental groups were formed: 40 patients with diffuse non-toxic goiter and type 2 diabetes mellitus and 501 patients with type 2 diabetes only. Each patient had ultrasound examination of thyroid gland. The size of thyroid gland was calculated by the Bruno method. Data of lipid profile, general blood analysis, level of insulin, glucose, biochemical blood analysis, thyroid hormones ( $\mathrm{TSH}, \mathrm{T}_{4}$ ) were defined. Statistical analysis was performed by calculating the median (Me), lower (Lq) and upper (Uq) quartiles, Mann-Whitney U-test.

Results. The average age of patients was 56 years. General blood analysis had significantly higher ESR levels by $63.6 \%$ in the group of T2D + diffuse non-toxic goiter in comparison with T2D. Significantly higher levels of HbA1C by $7.4 \%$, non-HDL-C by $3.57 \%$ in the group T2D + diffuse non-toxic goiter in comparison with T2D.

Conclusions. Patients with combined type 2 diabetes mellitus and diffuse non-toxic goiter have significantly higher levels of ESR, HbA1c, and progressive dyslipidemia due to non-HDL-C, compared with patients with type 2 diabetes mellitus only. There is a tendency to increase total and residual cholesterol in the group of T2D + diffuse non-toxic goiter compared with T2D. 
зильованого гемоглобіну, а також прогресує дисліпідемія за рахунок не-ХС-лПВЩ порівняно із хворими на цукровий діабет 2 типу.

Ключові слова: цукровий діабет 2 типу; дифузний нетоксичний зоб; коморбідність; лабораторні дані.

\section{ВСТУП}

Виробляючи гормони, щитоподібна залоза (ЩЗ) відіграє важливу роль у регулюванні метаболічних процесів організму людини. Йод $є$ важливим компонентом цих гормонів і його десріцит може сильно вплинути на їх продукцію [1]. Дифузний нетоксичний зоб (ДН3), як прояв гіперплазії щ3, є результатом компенсаторного збільшення вивільнення тиреотропного гормону (ТТГ) у результаті зниження рівня тироксину $\left(\mathrm{T}_{4}\right)$. ДНЗ $є$ показником хронічного дефіциту йоду та основною проблемою охорони здоров'я в кількох регіонах світу, особливо в країнах, що розвиваються. Близько 30 \% людей населення світу страждає від йододесріцитних розладів [1]. Поширеність ДНЗ зростає із збільшенням дефріциту йоду і стає ендемічним у популяціях, де споживання його становить менше 10 мкг на добу [2]. В даний час поширеність ДНЗ визначається за допомогою загальної частоти зоба, що еквівалентна відношенню кількості випадків зоба I та II ступенів, виявлених у населення, до загальної кількості обстежених [1]. Поширеність зоба у світі в загальній популяції становить 15,8 \%, варіюючи від 4,7 \% в Америці до 28,3 \% в Асриці [3]. За даними різних досліджень, основними сракторами ризику виникнення ДНЗ $є$ вік, стать, спадковий анамнез, рівень йоду в побутовій солі та соціальноекономічний статус [4-7]. Останнім часом науковці все більше приділяють уваги вивченню зв'язку між інсулінорезистентністю, яка є характерною ознакою цукрового діабету 2 типу, та аномальною фрункцією та морфологією щз. Проте асоціація між Цд2 та розладами щ3 недостатньо вивчена, зустрічаються дані щодо вищої поширеності диссрункції ЩЗ у пацієнтів із ЦД2 стосовно загальної популяції [8-10].

Метою дослідження було оцінити лабораторні показники у хворих із поєднаним перебігом цукрового діабету 2 типу та дифузним нетоксичним зобом i виявити можливі маркери їх коморбідності.

\section{МАТЕРІАЛИ I МЕТОДИ}

Для дослідження було виконано аналіз медичної документації 541 пацієнта, що перебували на лікуванні в ендокринологічному відділенні комунального некомерційного підприємства «Тернопільська університетська лікарня» Тернопільської обласної ради протягом 2019 року. Сформовано дві дослідні групи: 40 пацієнтів із дифузним нетоксичним зобом та цукровим діабетом 2 типу і 501 особа з діабетом 2 типу без патології щитоподібної залози.
Key words: type 2 diabetes mellitus; diffuse non-toxic goiter; comorbidity; laboratory data.

3 дослідження були виключені вагітні й ті, хто годує груддю, пацієнти із інфекційними або серйозними неврологічними чи психічними захворюваннями (депресія, тривога та шизофренія), а також тих, хто на момент дослідження приймав гормональні препарати, які можуть прямо чи опосередковано сприяти підвищенню схильності до захворювань щитоподібної залози.

Цукровий діабет 2 типу діагностували згідно 3 рекомендаціями Американської асоціації діабету при показнику глікозильованого гемоглобіну (HbA1c) $\geq 6,5$ \% [11]. ДН3 діагностували, якщо при пальпації щ3 кожна ії частка була більша, ніж термінальна фраланга великого пальця руки [12].

Кожному пацієнту виконували ультразвукове дослідження Щ3, поздовжнє та поперечне сканування, що дозволяє виміряти глибину (d), ширину (w) та висоту (h) кожної частки. Об'єм частки розраховували за методом Bruno [13]:

$$
V\left(\mathrm{~cm}^{3}\right)=0,479 * d * w * h,
$$

де $W, d, h$ - взаємо перпендикулярні розміри щ3; 0,479 коефіцієнт.

Об'єм щитоподібної залози - це сума об'ємів обох часток без розміру перешийка.

Визначення показників загального аналізу крові проводили на автоматичному гематологічному аналізаторі «Yumizen H500 CT», рівень інсуліну в крові визначали на імуноферментному аналізаторі фрірми «Thermo Scientific Multiskan FC», концентрацію глюкози, активність аланінамінотрассрерази (АлАТ) і аспартатамінотрансферази (АсАТ) визначали за допомогою стандартних наборів на автоматичному біохімічному аналізаторі фрірми COBAS INTEGRA $®$ 400 (Roche Diagnostics).

Показники ліпідного профрілю сироватки крові вимірювали у лабораторії Тернопільської університетської лікарні. Концентрацію загального холестеролу (3ХC), триацилгліцеролів (ТГ) холестеролу ліпопротеїнів високої щільності (ХС-ЛПВЩ) визначали за допомогою комерційно доступних наборів на аналізаторі Cobas 6000 (Roche Hitachi, Німеччина).

Індекс інсулінорезистентності HOMA-IR вираховували за допомогою показника глюкози натще (FPG) та інсуліну (FINS) за формулою: [14].

HOMA-IR $=$ FPG $(\mathrm{mmol} / \mathrm{L}) \times$ FINS $(\mathrm{m} / \mathrm{L} / \mathrm{L}) / 22,5$

Описову статистику здійснювали у вигляді розрахунку медіани (Me) та нижнього (Lq) і верхнього (Uq) квартилів. При оцінці рівня статистичної зна- 
чущості проводили попарне порівняння груп з використанням U-критерію Манна - Уїтні.

Статистичну обробку результатів здійснювали 3 використанням комп'ютерної програми STATISTICA 10.0. Залежність між показниками (кількісними, якісними) оцінювалася за допомогою коефріцієнта кореляції Спірмена $(\mathrm{R})$ незалежно від їх розподілу. Для оцінки вірогідності відмінностей між коесріцієнтами кореляції у двох групах застосовували опцію «тест відмінностей для коефіцієнтів кореляцій». При аналізі усіх типів даних значущими вважалися відмінності між групами при p<0,05; тенденцію щодо змін вказували в діапазоні 0,050<p<0,100.

\section{РЕЗУЛЬТАТИ Й ОБГОВОРЕННЯ}

Середній вік хворих у групі ЦД2 $56(50 ; 62)$ років та $58(55 ; 64,25)$ у групі ЦД2 + ДН3. Індекс маси тіла (IMT) у дослідних групах вірогідно не відрізнявся. У групі ЦД2 + ДНЗ 36 осіб жіночої статі, що становить 90 \%, та 4 особи чоловічої статі, що складає $10 \%$ відповідно. Разом з тим, у групі ЦД2 274 (54,7 \%) осіб чоловічої статі та 227 (45,3%) жіночої (табл. 1).
При аналізі показників загального аналізу крові (табл. 2) було виявлено вірогідно вищі показники шОЕ на 63,6 \% у групі ЦД2 + ДН3 порівняно з ЦД2 ( $<<0,001)$. Показники гемоглобіну, еритроцитів та КП вірогідно не відрізнялись між дослідними групами.

У групі хворих ЦД2 показники лейкоцитів становили $6,4(5,2 ; 7,6)$ * 10\% та $5,94(4,8 ; 7,75)$ * 10\% у у групі ЦД2 + ДН3 (p=0,4231), паличкоядрні нейтрофріли $5(3 ; 7)$ \% та $6(3 ; 7)$ \% (p=0,3604), сегментоядерні нейтрооріли 58 (50; 64) \% та 59 (54; 64) \% (p=0,9095), еозинофріли $1(1 ; 3) \%$ та $2(1 ; 3)$ $\%(p=0,1986)$, лімфроцити $31(25 ; 39) \%$ та $32(25 ;$ $37) \%(p=0,8381)$, моноцити $3(1 ; 5) \%$ та $3(2 ; 5) \%$ ( $p=0,4422)$ відповідно. Вірогідної відмінності при порівнянні лейкограми у дослідних групах виявлено не було (рис. 1).

При оцінці показників вуглеводного обміну (табл. 3) встановлено вірогідно вищі показники глікозильованого гемоглобіну на 7,4 \% у групі ЦД2 + ДН3 порівняно із ЦД2 (p=0,048). Показники глюкози натще, інсуліну та індексу HOMA-IR вірогідно не відрізнялись між дослідними групами.

Таблиця 1. Характеристика пацієнтів, включених у дослідження

\begin{tabular}{l|c|c|c|c}
\hline \multirow{2}{*}{ Група } & \multirow{2}{*}{ Вік } & \multirow{2}{*}{ ІМТ } & \multicolumn{2}{c}{ Стать } \\
\cline { 3 - 5 } & & & чоловіки, $\mathrm{n}(\%)$ & жінки, $\mathrm{n}(\%)$ \\
\hline Цд2 & $56(50 ; 62)$ & $30,48(26,29 ; 34,22)$ & $274(54,7)$ & $227(45,3)$ \\
\hline ЦД2 + ДН3 & $58(55 ; 64,25)$ & $31,42(28,13 ; 35,35)$ & $4(10)$ & $36(90)$ \\
\hline p-value & 0,139 & 0,1637 & \multicolumn{2}{|c}{$<0,001^{*}$} \\
\hline
\end{tabular}

Примітка. Тут і в наступних таблицях: * - статистично вірогідна відмінність.

Таблиця 2. Зіставлення показників загального аналізу крові у пацієнтів із коморбідним перебігом цукрового діабету 2 типу і дисрузним нетоксичним зобом стосовно хворих із цукровим діабетом 2 типу

\begin{tabular}{l|c|c|c|c}
\hline \multicolumn{1}{c|}{ Група } & Гемоглобін (г/л) & Еритроцити $\left(10^{12}\right)$ & КП & ШОЕ (мм/год) \\
\hline ЦД2 & $138(127 ; 149)$ & $4,4(4 ; 4,7)$ & $0,9(0,9 ; 1)$ & $11(6 ; 20)$ \\
\hline ЦД2 + ДН3 & $130(127 ; 145)$ & $4,25(4 ; 4,56)$ & $0,95(0,9 ; 1)$ & $18(12 ; 24)$ \\
\hline p-value & 0,284 & 0,2666 & 0,05993 & $0,0003411^{*}$ \\
\hline
\end{tabular}

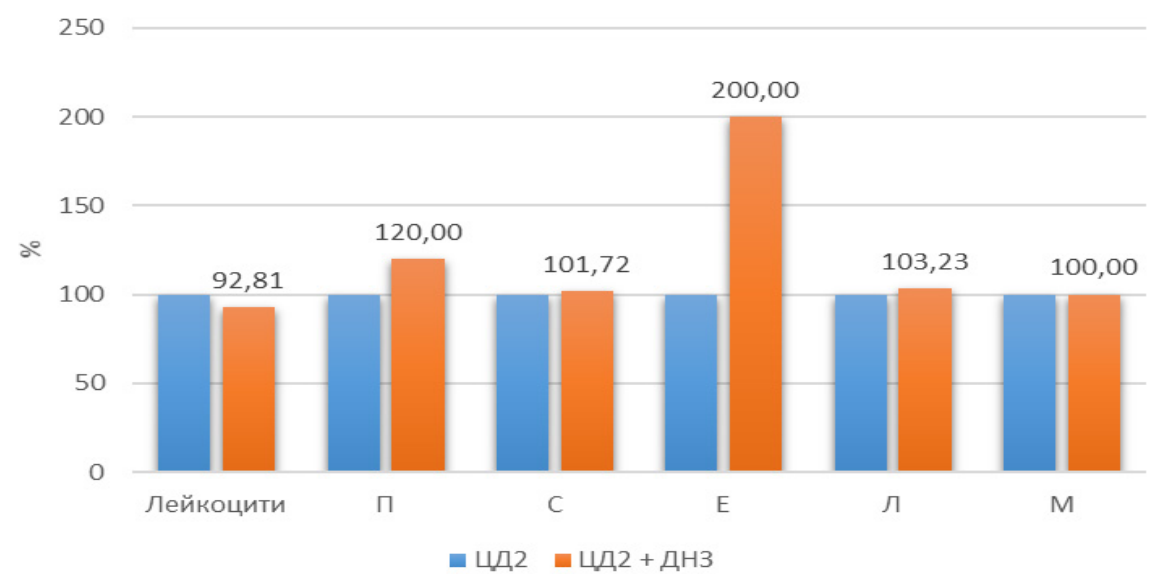

Рис. 1. Зіставлення (\%) показників лейкограми у хворих із коморбідним перебігом цукрового діабету 2 типу та дифузним нетоксичним зобом стосовно даних пацієнтів із цукровим діабетом 2 типу (П - паличкоядерні нейтросріли, С - сегментоядерні нейтрофріли, Е - еозинофіли, Л - лімфоцити, М - моноцити). 
Таблиця 3. Показники вуглеводного обміну в пацієнтів із коморбідним перебігом цукрового діабету 2 типу з дифузним нетоксичним зобом порівняно із хворими на цукровий діабет 2 типу

\begin{tabular}{l|c|c|c|c}
\hline \multicolumn{1}{c|}{ Група } & $\begin{array}{c}\text { Глікемія натще } \\
\text { (ммоль/л) }\end{array}$ & $\begin{array}{c}\text { Глікозильований } \\
\text { гемоглобін (\%) }\end{array}$ & Інсулін (мМО/мл) & HOMA-IR \\
\hline ЦД2 & $9,4(7,5 ; 12,1)$ & $8,1(6,99 ; 9,3)$ & $13,85(9,87 ; 17,34)$ & $5,59(4,58 ; 6,87)$ \\
\hline ЦД2 + ДН3 & $8,49(7,84 ; 10,18)$ & $8,7(7,6 ; 10,09)$ & $15,02(10,75 ; 18,71)$ & $5,85(4,56 ; 6,72)$ \\
\hline p-value & 0,1476 & $0,04841^{*}$ & 0,1875 & 0,8351 \\
\hline
\end{tabular}

Досліджуючи показники біохімічного аналізу крові, не виявлено вірогідних змін вмісту загального протеїну у групі ЦД2 + ДН3, що складав 73,2 $(69,08 ; 75,85)$ Г/л порівняно з ЦД2 - 71,1 $(67,6 ; 75)$ Г/л ( $p=0,07515)$. Також не встановлено статистично значимої різниці між іншими досліджуваними біохімічними показниками, зокрема рівень креатиніну в групі ЦД2 складав 71 (60;85) мкмоль/л та 66,5 (56; $75,65)$ мкмоль/л у ЦД2 + ДНЗ ( $p=0,1281)$, сечовини - 5,4 (4,3; 6,8) мкмоль/л та 5,65 (4,65; 6,83) мкмоль/л ( $p=0,6634)$, АлАТ - 19,9 (14; 29,6) Од/л та 21,05 (13,2; $27,6)$ Од/л (p=0,7418), АсАТ - 18,1 (14,2; 25,8) Од/л та $18,2(13,25 ; 24,68)$ Од/л ( $p=0,5771)$, загального білірубіну - $9(6 ; 13,6)$ мкмоль/л та 9,95 $(7,58 ; 13,78)$ мкмоль/л ( $p=0,2725)$, загальної амілази - $44(34 ; 66)$ Од/л та $38(34,25 ; 53,25)$ Од/л $(p=0,4345)$ відповідно (рис. 2).
Показники не-ХС-лПВЩ на 3,57 \% вищі у групі ЦД2 + ДНЗ, порівняно із ЦД2, що статистично достовірно ( $p=0,0359)$. Відмічається тенденція до підвищення загального та залишкового холестеролу у групі ЦД2 + ДН3 порівняно із ЦД2 ( $p=0,07169$ та p=0,05297 відповідно). Показники ХС-лПВЩ, ХСлПНЩ, ТГ вірогідно не відрізнялись у дослідних групах (табл. 4).

При оцінці фрункції щЗ вірогідної різниці у показниках гормонів щ3 (ТТГ та $\mathrm{T}_{4}$ ) між пацієнтами 3 ЦД2 та коморбідними ЦД2 і ДНЗ виявлено не було (табл. 5).

Загальний об'єм ЩЗ у хворих із коморбідним перебігом ЦД2 та ДН3 вірогідно вищий на $34.5 \%$, ніж у хворих лише на ЦД2 ( $=0.04264)$ (табл. 6).

Результати ряду наукових досліджень показали вплив певних фракторів на ризик розвитку зоба у

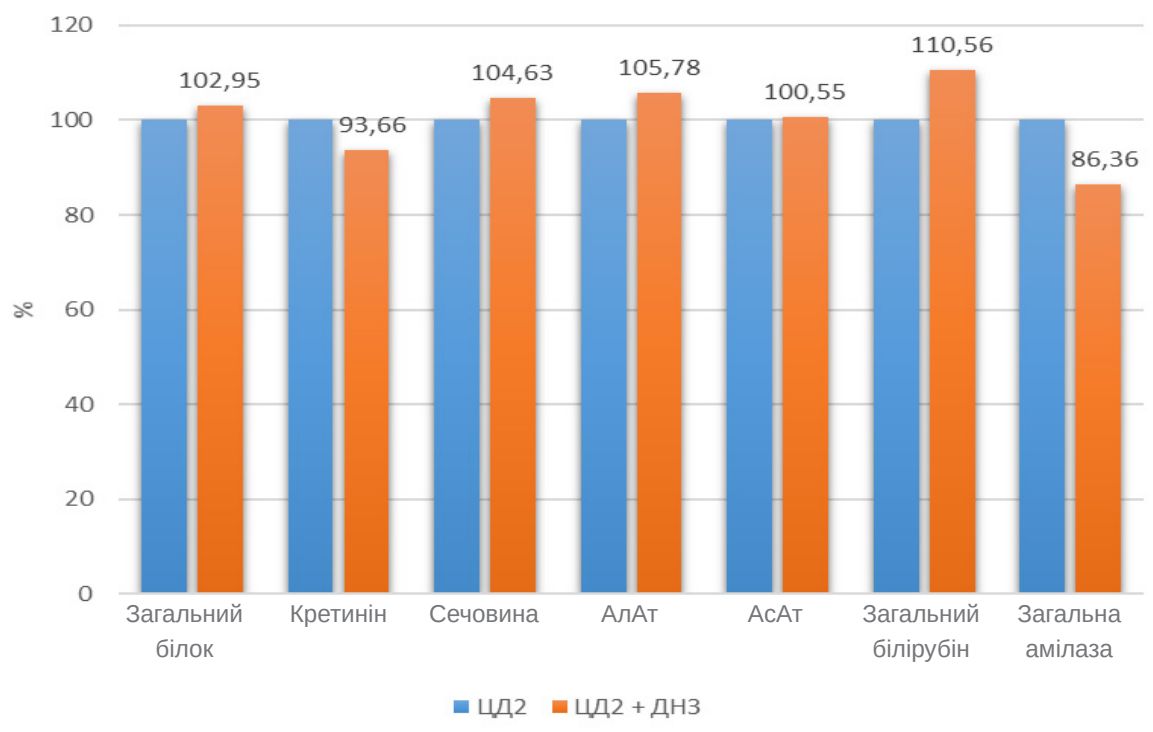

Рис. 2. Зіставлення (\%) показників біохімічного аналізу крові у хворих із коморбідним перебігом цукрового діабету 2 типу та дифузним нетоксичним зобом стосовно даних пацієнтів із цукровим діабетом 2 типу.

Таблиця 4. Показники ліпідограми у пацієнтів із коморбідним перебігом цукрового діабету 2 типу з дифруним нетоксичним зобом порівняно із хворими на цукровий діабет 2 типу

\begin{tabular}{l|c|c|c|c|c|c}
\hline \multicolumn{1}{|c|}{ Група } & $\begin{array}{c}\text { ЗХС } \\
\text { (ммоль/л) }\end{array}$ & $\begin{array}{c}\text { ХС-ЛПВЩ } \\
\text { (ммоль/л) }\end{array}$ & $\begin{array}{c}\text { ХС-ЛПНЩ } \\
\text { (ммоль/л) }\end{array}$ & $\begin{array}{c}\text { Залишковий ХС } \\
\text { (ммоль/л) }\end{array}$ & $\begin{array}{c}\text { Не ХС- ЛПВЩ } \\
\text { (ммоль/л) }\end{array}$ & ТГ (ммоль/л) \\
\hline цд2 & $\begin{array}{c}4,99(4,28 ; \\
5,88)\end{array}$ & $1,1(0,95 ; 1,24)$ & $3,05(2,4 ; 3,9)$ & $0,75(0,44 ; 1,18)$ & $3,92(3,21 ; 4,68)$ & $1,83(1,09 ; 2,8)$ \\
\hline $\begin{array}{l}\text { ЦД2+ } \\
\text { ДН3 }\end{array}$ & $\begin{array}{c}5,25(4,72 ; \\
5,98)\end{array}$ & $1,04(0,82 ; 1,32)$ & $3,2(2,75 ; 4,07)$ & $0,96(0,64 ; 1,2)$ & $4,06(3,58 ; 4,83)$ & $\begin{array}{c}2,14(1,41 ; \\
2,66)\end{array}$ \\
\hline p-value & 0,07169 & 0,3164 & 0,9431 & 0,05297 & $0,0359^{*}$ & 0,4757 \\
\hline
\end{tabular}


Таблиця 5. Показники гормонів щитоподібної залози у хворих на цукровий діабет 2 типу із коморбідним дисрузим нетоксичним зобом порівняно з пацієнами з цукровим діабетом 2 типу

\begin{tabular}{l|c|c}
\hline \multicolumn{1}{|c|}{ Група } & ТТГ (мкМО/мл) & Тироксин (пмоль/л) \\
\hline ЦД2 & $1,94(1,57 ; 2,84)$ & $16,04(14,95 ; 17,23)$ \\
\hline ЦД2 + ДН3 & $1,69(0,88 ; 3,46)$ & $14,8(12,43 ; 17,6)$ \\
\hline p-value & 0,3927 & 0,3504 \\
\hline
\end{tabular}

Таблиця 6. Дані ультразвукового дослідження щитоподібної залози у пацієнтів із коморбідним перебігом цукрового діабету 2 типу з дисузним нетоксичним зобом порівняно із хворими на цукровий діабет 2 типу

\begin{tabular}{|c|c|c|c|c|}
\hline Група & Загальний об'єм (см³) & Права частка $\left(\mathrm{cm}^{3}\right)$ & Ліва частка $\left(\mathrm{cm}^{3}\right)$ & Перешийок (мм) \\
\hline ЦД2 & $11,6(9,1 ; 15,2)$ & $6,1(4,5 ; 7,2)$ & $6,1(4,6 ; 8)$ & $5(3,7 ; 5,45)$ \\
\hline ЦД2 + ДН3 & $15,6(12,73 ; 20,1)$ & $8,1(6,55 ; 10.13)$ & $7,95(5,6 ; 9,5)$ & $5(4,28 ; 6,23)$ \\
\hline p-value & $0,04264 *$ & $0,03415^{*}$ & 0,06859 & 0,3091 \\
\hline
\end{tabular}

хворих на ЦД2, зокрема вік, стать, індекс маси тіла, HbA1c, індекс HOMA-IR, ТTГ, T. Так, Y. Tang et al. доводять, що вік пацієнтів, стать, T та HOMA-IR можуть бути фракторами ризику виникнення вузлового зоба в хворих на ЦД2 [15]. Згідно з дослідженнями Gebremichael et al., у жінок майже вдвічі більші ризики виникнення зоба, порівняно з чоловіками [16], тоді як у дослідженні Heidari та колег, 86,7 \% пацієнтів із вузловим зобом були жіночої статі [17].

Ще одним і критеріїв диорузного зоба є збільшення об'єму щЗ. Результати нашого дослідження показували, що вірогідне збільшення загального об'єму щ3, в основному за рахунок достовірного збільшення правої частки ( $p=0,034)$ у хворих на ЦД2 і ДНЗ відносно даних пацієнтів тільки з Цд2. У дослідженні Blanc et al. було встановлено взаємозв'язок між об'ємом Щ3 та рівнем HbA1c ( $r=0,261 ; p=0,027)$ [18]. Крім того, дані дослідники відмітили, що пацієнти з цукровим діабетом мали значно більші об'єми щз, ніж недіабетики.

\section{ВИСНОВКИ}

У хворих із поєднаним перебігом цукрового діабету 2 типу та дифузного нетоксичного зоба виявляється вірогідно вищий рівень ШОЕ ( $p=0,00034)$, глікозильованого гемоглобіну $(p=0,48)$, а також прогресує дисліпідемія за рахунок не-ХС-лПВЩ $(p=0,036)$ порівняно із хворими на цукровий діабет 2 типу.

\section{СПИСОК ЛІТЕРАТУРИ}

1. World Health Organization. Goitre as a Determinant of the Prevalence and Severity of Iodine Deficiency Disorders in Populations. World Health Organization. - Geneva, Switzerland: World Health Organization. - 2014.

2. Hetzel B. S. The story of iodine deficiency: an international challenge in nutrition / B. S. Hetzel // Oxford and New Delhi: Oxford University Press. - 1989.

3. Iodine Status Worldwide, WHO Global Database on Iodine Deficiency: Department of Nutrition for Health and Development / M. Andersson, B. Takkouche, I. Egli [et al.] // Geneva, Switzerland: World Health Organization; 2004.

4. Mesele M. Prevalence and associated factors of goiter among rural children aged 6-12 years old in Northwest Ethiopia, cross-sectional study / M. Mesele, G. Degu, H. Gebrehiwot // BMC Public Health. - 2014. - Vol. 14. P. 130.

5. Anusha A. Evaluation of Goitre and its sociodemographic risk factors among rural school children of Kancheepuram, Tamil Nadu, India / A. Anusha, S. Gopalakrishnan, A. Savitha // J. Clin. Diagn. Res. - 2018. - Vol. 12 (6). - P. 10-14.

6. Relationship between goiter and gender: a systematic review and meta-analysis / R. Malboosbaf, F. Hosseinpanah, M. Mojarrad [et al.] // Int. J. Basic Clin. Endocrinol. - 2013. - Vol. 43. - P. 539
7. Cho Y. A. Dietary factors affecting thyroid cancer risk: A meta-analysis / Y. A. Cho, J. Kim // Nutr. Cancer. - 2015. - Vol. 67, No. 5. - P. 811-817.

8. Han C. Subclinical hypothyroidism and type 2 diabetes: A systematic review and meta-Analysis / C. Han, X. He, X. Xia // PLoS One. - 2015. - Vol. 10, No. 8. P. e0135233.

9. Smithson M. J. Screening for thyroid dysfunction in a community population of diabetic patients / M. J. Smithson // Diabet Med. - 1998. - Vol. 15, No. 2. - P. 148-150.

10. Al-Geffari M. Risk factors for thyroid dysfunction among type 2 diabetic patients in a highly diabetes Mellitus Prevalent Society / M. Al-Geffari, N. A. Ahmad, A. H. Al-Sharqawi [et al.] // Int .J. Endocrinol. -2013. -2013. P. 417920.

11. American Diabetes Association. 10. Cardiovascular Disease and Risk Management: Standards of Medical Care in Diabetes-2019 / American Diabetes Association // Diabetes Care. - 2019. - Vol. 42, Suppl. 1. - P. S103-S123.

12. Assessment of iodine deficiency disorders and monitoring their elimination. Aguide for programme managers [Internet] / WHO/UNICEF/ICCIDD // 3rd ed. Geneva: World Health Organization. - 2007. - Available from: http:// whqlibdoc.who.int/publications/2007/9789241595827_eng. pdf 
13. Volumetric analysis of thyroid lobes by real-time ultrasound (author's transl) / J. Brunn, U. Block, G. Ruf [et al.] // Dtsch. Med. Wochenschr. - 1981. - Vol. 106, No. 41. - P. 1338-1340.

14. Homeostasis model assessment closely mirrors the glucose clamp technique in the assessment of insulin sensitivity: studies in subjects with various degrees of glucose tolerance and insulin sensitivity / E. Bonora, G. Targher, M. Alberiche [et al.] // Diabetes Care. - 2000. Vol. 23, No. 1. - P. 57-63.

15. Correlation between insulin resistance and thyroid nodule in type 2 diabetes mellitus / Y. Tang, T. Yan, G. Wang [et al.] // International Journal of Endocrinology. - 2017. 2017. - P. 1617458.

\section{REFERENCES}

1. World Health Organization. Goitre as a Determinant of the Prevalence and Severity of lodine Deficiency Disorders in Populations. Geneva, Switzerland: World Health Organization. 2014.

2. Hetzel BS. The story of iodine deficiency: an international challenge in nutrition. Oxford and New Delhi: Oxford University Press. 1989.

3. M. Andersson, B. Takkouche, I. Egli. Iodine Status Worldwide, WHO Global Database on lodine Deficiency: Department of Nutrition for Health and Development Geneva, Switzerland: World Health Organization. 2004

4. Mesele M, Degu G, Gebrehiwot H. Prevalence and associated factors of goiter among rural children aged 6-12 years old in Northwest Ethiopia, cross-sectional study. BMC Public Health. 2014;14: 130.

5. Anusha A, Gopalakrishnan S, Savitha A. Evaluation of Goitre and its sociodemographic risk factors among rural school children of Kancheepuram, Tamil Nadu, India. J Clin Diagn Res. 2018;12(6): 10-4.

6. Malboosbaf R, Hosseinpanah F, Mojarrad M. Relationship between goiter and gender: a systematic review and meta-analysis. Int J Basic Clin Endocrinol. 2013;43: 539.

7. Cho YA, Kim J. Dietary factors affecting thyroid cancer risk: A meta-analysis. Nutr Cancer. 2015;67(5): 811-7.

8. Han C, He X, Xia X, Li Y, Shi X, Shan Z, et al. Subclinical Hypothyroidism and Type 2 Diabetes: A Systematic Review and Meta-Analysis. PLoS One. 2015;10(8): e0135233.

9. Smithson MJ. Screening for thyroid dysfunction in a community population of diabetic patients. Diabet Med. 1998;15(2): 148-50.

10. Al-Geffari M, Ahmad NA, Al-Sharqawi AH, Youssef AM, Alnaqeb D, Al-Rubeaan K. Risk factors for thyroid
16. Prevalence of goiter and associated factors among adolescents in Gazgibla District, Northeast Ethiopia / G. Gebremichael, M. Demena, G. Egata, B. Gebremichael // Glob. Adv. Health Med. - 2020. - Vol. 9. - P. 2164956120923624

17. Heidari Z. Insulin resistance in patients with benign thyroid nodules / Z. Heidari, M. A. Mashhadi, S. Nosratzehi // Arch. Iran Med. - 2015. - Vol. 18, No. 9. - P. 572-576.

18. Association between worse metabolic control and increased thyroid volume and nodular disease in elderly adults with metabolic syndrome / E. Blanc, C. Ponce, D. Brodschi [et al.] // Metab. Syndr. Relat. Disord. - 2015. Vol. 13, No. 5. - P. 221-226.

dysfunction among type 2 diabetic patients in a highly diabetes mellitus prevalent society. Int $\mathrm{J}$ Endocrinol. 2013;2013: 417920.

11. American Diabetes Association. 10. Cardiovascular Disease and Risk Management: Standards of Medical Care in Diabetes-2019. Diabetes Care. 2019;42(Suppl 1): S103-S23.

12. WHO/UNICEF/ICCIDD. Assessment of iodine deficiency disorders and monitoring their elimination. A guide for programme managers 3rd ed. Geneva: World Health Organization. 2007. Available from: http://whqlibdoc. who.int/publications/2007/9789241595827_eng.pdf

13. Brunn J, Block U, Ruf G, Bos I, Kunze WP, Scriba PC. Volumetric analysis of thyroid lobes by real-time ultrasound (author's transl). Dtsch Med Wochenschr. 1981;106(41): 1338-40.

14. Bonora E, Targher G, Alberiche M, Bonadonna RC, Saggiani F, Zenere MB, et al. Homeostasis model assessment closely mirrors the glucose clamp technique in the assessment of insulin sensitivity: studies in subjects with various degrees of glucose tolerance and insulin sensitivity. Diabetes Care. 2000;23(1): 57-63.

15. Tang Y, Yan T, Wang G, et al. Correlation between insulin resistance and thyroid nodule in type 2 diabetes mellitus. International Journal of Endocrinology. 2017;2017: 1617458

16. Gebremichael G, Demena M, Egata G, Gebremichael B. Prevalence of Goiter and Associated Factors Among Adolescents in Gazgibla District, Northeast Ethiopia. Glob Adv Health Med. 2020;9: 2164956120923624.

17. Heidari Z, Mashhadi MA, Nosratzehi S. Insulin resistance in patients with benign thyroid nodules. Arch Iran Med. 2015;18(9): 572-6. 